\title{
Rythme du sinus coronaire
}

\section{Coronary sinus rhythm}

\section{P. Taboulet}

Reçu le 15 juin 2010 ; accepté le 20 juin 2010

(C) SFMU et Springer-Verlag France 2011

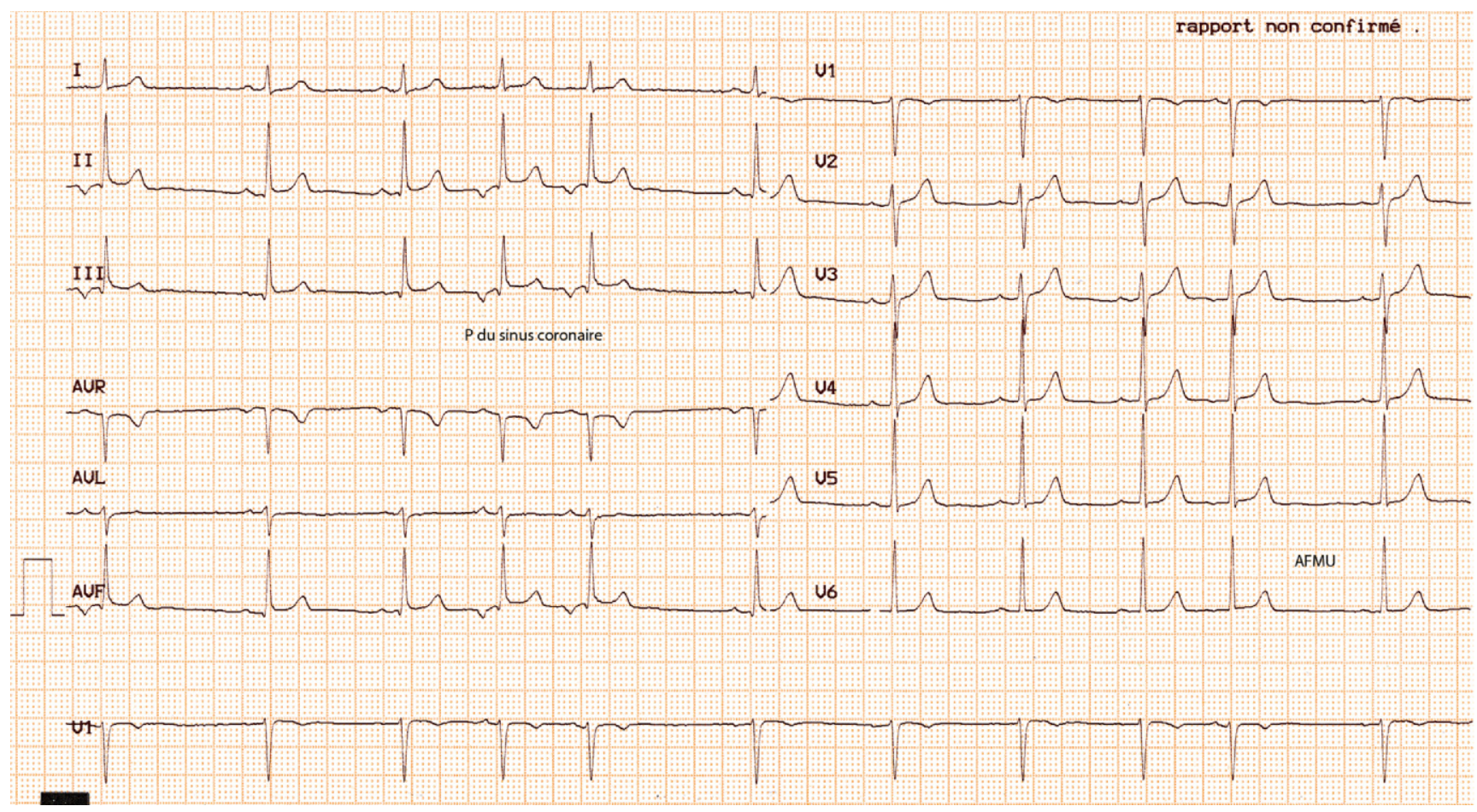

Fig. 1 Rythme sinusal en alternance avec un rythme du sinus coronaire

Une jeune femme de 22 ans consulte aux urgences pour une lipothymie d'allure vagale. L'ECG révèle un rythme sinusal (ondes $\mathrm{P}$ positives en D2-D3-VF) en alternance, selon la respiration, avec un rythme atrial ectopique plus rapide (ondes $\mathrm{P}$ négatives en D2-D3-VF et P-R un peu plus court en V1). Ce rythme atrial accéléré provient de cellules automatiques accessoires situées près de la veine cave inférieure et proche du sinus coronaire (d'où son nom de « rythme du

\section{P. Taboulet $(\bowtie)$}

Service des urgences,

hôpital Saint-Louis-Lariboisière-Fernand-Widal,

Assistance publique-Hôpitaux de Paris, université Denis-Diderot,

1, avenue Claude-Vellefaux, F-75010 Paris, France

e-mail : pierre.taboulet@sls.aphp.fr sinus coronaire ») (Fig. 1). Ce pacemaker accessoire est particulièrement actif chez certains sujets et n'a pas de valeur pathologique. Le sus-décalage du segment ST contemporain du rythme atrial ectopique illustre l'influence de la repolarisation atriale sur la repolarisation ventriculaire [1].

\section{Référence}

1. Ihara Z, van Oosterom A, Hoekema R (2006) Atrial repolarization as observable during the PQ interval. J Electrocardiol 39:290-7 